\title{
Erratum to: Behavioral and ecological factors account for variation in the mass-independent energy expenditures of endotherms
}

\section{B. K. McNab}

Published online: 29 October 2014

(C) Springer-Verlag Berlin Heidelberg 2014

\section{Erratum to: J Comp Physiol B}

\section{DOI 10.1007/s00360-014-0850-z}

The authors would like to correct the errors in the online published article.

In the original publication, the values of $\log _{10}$ intercept and BMR in Table 1 were incorrectly published as -1.230 and 0.059 respectively. The values should be replaced by -1.297 and 0.050 . The corrected table is given in adjacent page.
Also the legend to Fig. 2 and Fig. 6 should read as:

Fig. 2 a $\log _{10}$ measured basal rates of metabolism in phyllostomid bats as a function of $\log _{10}$ body mass. $\mathbf{b}$ measured basal rates of metabolism as a function of the basal rates calculated from Eq. (1). Fig. $6 \log _{10}$ basal rate of metabolism of 533 species of birds as a function of $\log _{10}$ body mass in a 272 passerines and b 261 non-passerines (McNab 2009). The fitted coefficient equals $0.130 \mathrm{~kJ} / \mathrm{h}$ for passerines and $0.089 \mathrm{~kJ} / \mathrm{h}$ for non-passerines.

The online version of the original article can be found under doi: 10.1007/s00360-014-0850-z.

B. K. McNab ( $₫)$

Department of Biology, University of Florida, Gainesville,

FL 32611, USA

e-mail: bkm@ufl.edu 
Table 1 An analysis of the energetics of phyllostomid bats

\begin{tabular}{|c|c|c|c|}
\hline \multicolumn{4}{|l|}{ 1. $\mathrm{BMR}(\mathrm{kJ} / \mathrm{h})=f$ (mass) } \\
\hline $\log _{10}$ mass $\times 0.673$ & \multicolumn{3}{|l|}{$P<0.0001$} \\
\hline $\log _{10}$ intercept $=-1.089$ & \multicolumn{3}{|l|}{$P<0.0001$} \\
\hline \multicolumn{4}{|c|}{$\log _{10} \mathrm{BMR}=0.673 \times \log _{10}$ mass $-1.089 ; r^{2}=0.788 \mathrm{BMR}=0.081 \mathrm{~m}^{0.673}$} \\
\hline \multicolumn{4}{|l|}{ 2. $\mathrm{BMR}(\mathrm{kJ} / \mathrm{h})=f$ (mass, food, distribution, altitude) } \\
\hline $\log _{10}$ mass $\times 0.749$ & \multicolumn{3}{|l|}{$P<0.0001$} \\
\hline $\log _{10}$ intercept $=-1.297$ & \multicolumn{3}{|l|}{$P<0.0001$} \\
\hline $\log _{10}$ food & \multicolumn{3}{|l|}{$P<0.0001$} \\
\hline $\log _{10}$ distribution & \multicolumn{3}{|l|}{$P<0.0001$} \\
\hline $\log _{10}$ altitude & \multicolumn{3}{|l|}{$P<0.0001$} \\
\hline \multicolumn{4}{|c|}{$\log _{10} \mathrm{BMR}=\left(\log _{10} F \times \log _{10} D \times \log _{10} A\right) 0.749\left(\log _{10}\right.$ mass $)-1.297 ; r^{2}=0.987$} \\
\hline \multicolumn{4}{|l|}{$\mathrm{BMR}=0.050(F \times D \times A) \mathrm{m}^{0.749}$} \\
\hline Coefficients: & $\log _{10}$ mean least squares & Anti-log coefficients & Statistical level \\
\hline 1. Food (nectar/fruit, nectar/insect, Piper) & 1.528 & 1.00 & A \\
\hline 2. Food (vertebrate/insect, vertebrate, Gutterferae, fig) & 1.453 & 0.84 & $\mathrm{~B}$ \\
\hline 3. Food (omnivore, bird blood) & 1.354 & 0.67 & $\mathrm{C}$ \\
\hline 4 Food (insects, bird/mammal blood) & 1.281 & 0.57 & $\mathrm{D}$ \\
\hline \multicolumn{4}{|l|}{ Distribution } \\
\hline Continent & 1.531 & 1.79 & A \\
\hline Islands & 1.277 & 1.00 & $\mathrm{~B}$ \\
\hline \multicolumn{4}{|l|}{ Altitude } \\
\hline$>2,000 \mathrm{~m}$ & 1.460 & 1.29 & A \\
\hline$<2,000 \mathrm{~m}$ & 1.348 & 1.00 & $\mathrm{~B}$ \\
\hline
\end{tabular}

The data from which this analysis is made are found in McNab (2003b)

ANCOVA determines the coefficient that is the standard (equal to 1.00) to which the other coefficients in the same character or factor are compared

The coefficients in a character or factor are significantly different by Student's $t$ if the conditions are not connected by the same letter

Foods are grouped in a statistical analysis when the 11 individual food habits are entered as an independent unit and ranked in order by theirleast mean squares 